\title{
PERCEPÇÃO DA MULHER FRENTE À DOR DO PARTO
}

\author{
Woman perception ante of childbirth pain \\ Percepción de las mujeres sobre el dolor de parto
}

Klecianne da Costa Firmino • Enfermeira pelo Centro Universitário Tabosa de Almeida/ASCES-UNITA • Especialista em Saúde da mulher (Ginecologia e Obstetrícia) pelo Instituto de Desenvolvimento Educacional/IDE • E-mail: klecianne_costa@hotmail.com Elyda Priscila de Lima • Enfermeira pelo Centro Universitário Tabosa de Almeida/ ASCES-UNITA • Especialista em Saúde da mulher (Obstetrícia e Ginecologia) pelo Instituto de Desenvolvimento Educacional/IDE • E-mail: elydapl@gmail.com

Tamirys Renata Lima Correia • Enfermeira pelo Centro Universitário Tabosa de Almeida/ASCES-UNITA • Especialista em UTI neonatal e pediátrica pelo Instituto de Desenvolvimento Educacional/IDE E-mail: tamirys.lima4@hotmail.com Júlio César Bernardino da Silva • Enfermeiro pelo Centro Universitário Tabosa de Almeida/ ASCES-UNITA • Residente em Enfermagem Obstétrica pela Secretaria de Saúde do Recife/SESAU • Participante do Instituto de Estudos Avançados do Centro Universitário Tabosa de Almeida/ ASCESUNITA • E-mail: cesarsilva04@hotmail.com

Nayale Lucinda Andrade Albuquerque • Enfermeira • Doutoranda em Saúde Integral pelo Instituto de Medicina Integral Professor Fernando Figueira-IMIP • Docente e Pesquisadora do Instituto de Estudos Avançados do Centro Universitário Tabosa de Almeida/ASCES-UNITA• E-mail: nayalealbuquerque@asces.edu.br

Autora responsável pela correspondência:

Klecianne da Costa Firmino • E-mail: klecianne_costa@hotmail.com 


\section{RESUMO}

Introdução: As mulheres estão rodeadas por expectativas dos medos que permeiam o trabalho de parto, por isso atribuem significados a partir da experiência vivida, formando diversas percepções sobre a dor, minimizando os efeitos negativos após obter a satisfação de ser mãe. Objetivo: Conhecer a percepção da mulher frente à dor do parto. Método: Estudo descritivo, de abordagem qualitativa, realizado numa maternidade referência secundária para gestação de alto risco em Caruaru-PE no período de julho a agosto de 2016. Participaram desta pesquisa 13 mulheres que se encontravam no pós-parto mediato e imediato, após a experiência do parto normal de baixo risco. A entrevista foi realizada após leitura e assinatura do termo de consentimento livre e esclarecido e as falas das participantes foram submetidas à técnica de análise de conteúdo de Bardin. O estudo só foi iniciado após aprovação pelo Comitê de Ética em Pesquisa. Resultados: As mulheres atribuíram a dor do parto normal com o significado negativo no sentido de ser uma experiência inexplicável, horrível, uma dor insuportável. Entretanto, atribuíram também positivamente a experiência como prazerosa diante de uma dor tolerável e passageira, com uma recuperação rápida e regada de emoções. Conclusões: As mulheres possuem uma percepção variada da dor do parto, perpassando a compreensão de que é algo predeterminado por Deus, é algo natural e, por mais que essa dor seja insuportável, é algo passageiro, pois logo que a criança nasce todo esse processo doloroso é esquecido, gerando prazer e satisfação em ser mãe, por isso é importante uma atenção humanizada ao parto para que esse momento seja uma experiência prazerosa na vida da mulher.

Palavras-Chave: Dor do Parto; Pesquisa Qualitativa; Parto Normal

\section{ABSTRACT}

Introduction: Women are surrounded by expectations of fears that permeate labor, so they attribute meanings from their experience, forming various perceptions about pain, minimizing the negative effects after obtaining the satisfaction of being a mother. Objective: Know the perception of women facing the pain of childbirth. Methods: This is a descriptive, qualitative study conducted in a secondary reference maternity hospital for high-risk pregnancy in CaruaruPE from July to August 2016. Thirteen women who were in the immediate and immediate postpartum, after the experience of the study, participated in this research. low-risk normal delivery. The interview was conducted after reading and signing the free and informed consent form and the participants' statements were submitted to Bardin's content analysis technique. The study was only tarted after approval by the Research Ethics Committee. Results: Women tributed the pain of normal childbirth to the negative meaning that it was an explicable, horrible, unbearable pain. However, they also positively attributed 
the experience as pleasurable in the face of a tolerable and fleeting pain, with a quick and watery recovery of emotions. Conclusions: Women have a varied perception of the pain of childbirth, passing through the understanding that it is predetermined by God, it is natural and, as much as this pain is unbearable, it is transient, because as soon as the child is born all this painful process is forgotten, generating pleasure and satisfaction in being a mother, so a humanized attention to childbirth is important for this moment to be a pleasurable experience in the woman's life.

Keywords: Childbirth Pain; Qualitative Search; Normal Childbirth

\section{RESUMEN}

Introducción: Las mujeres están rodeadas de expectativas de los temores que permean el parto, por lo que atribuyen significados a partir de su experiencia, formando diversas percepciones sobre el dolor, minimizando los efectos negativos después de obtener la satisfacción de ser madre. Objetivo: Conozca la percepción de las mujeres que enfrentan el dolor del parto. Método: Este es un estudio descriptivo y cualitativo realizado en un hospital de maternidad de referencia secundario para embarazos de alto riesgo en Caruaru-PE de julio a agosto de 2016. Trece mujeres que estaban en el posparto inmediato e inmediato, después de la experiencia del estudio, participaron en esta investigación. parto normal de bajo riesgo. La entrevista se realizó después de leer y firmar el formulario de consentimiento libre e informado y las declaraciones de los participantes se enviaron a la técnica de análisis de contenido de Bardin. El estudio solo comenzó después de la aprobación del Comité de Ética en Investigación. Resultados: Como múltiples atribuyen a un dor do parto normal con un significado negativo sin sentido de ser una experiencia inexplicable, horvelvel, uma dor insuportável. Entretanto, atribuíram también positivamente una experiencia como prazerosa diante de uma dor tolerável y Passira, com uma recuperação rápida e regada de emoções. Conclusiones: Las mujeres tienen una percepción variada del dolor del parto, pasando por el entendimiento de que es algo predeterminado por Dios, es natural y, por mucho que este dolor sea insoportable, es algo temporal, porque tan pronto como nace el niño, este proceso doloroso es olvidado, generando placer y satisfacción en ser madre, por lo que una atención humanizada al parto es importante para que este momento sea una experiencia placentera en la vida de la mujer.

Palabras Clave: Dolor de parto; Investigación cualitativa; Parto normal 


\section{Introdução}

Segundo historiadores bíblicos, a dor do parto foi designada por Deus como uma punição, sendo relacionado com a necessidade de vivência da dor como um processo de purgação do pecado. Em Gênesis, Deus sentenciou para a mulher: "Multiplicarei grandemente o teu sofrimento na gravidez, em meio a agonia darás à luz filhos". ${ }^{1}$ Dentro da perspectiva histórica o conceito da dor se amplia, sendo assim destacada por estudiosos que a dor é tida como um elemento ruim.

Na história da antropologia, a interpretação cultural da dor remonta às mitologias primitivas e arcaicas que tinham uma concepção dualista: bem e mal. Os humanos primitivos faziam parte da ecologia ambiental e tinham da dor uma imagem associada ao mal e ao sofrimento, considerada coisa de inimigo, que provoca danos. ${ }^{2}$

As mulheres estão rodeadas por expectativas dos medos que permeiam o trabalho de parto, por isso atribuem significados a partir da experiência vivida, formando diversas percepções sobre a dor, minimizando os efeitos negativos após obter a satisfação de ser mãe.

A parturição pode ser vivida como uma experiência prazerosa ou traumática, sendo que esta vivência é influenciada pelo grau de maturidade da mulher, pelas experiências pessoais e familiares anteriores, assim como pela assistência recebida durante o pré-natal e o parto. ${ }^{3}$

Uma equipe de saúde ausente traz ainda mais angústia e ansiedade para a gestante, piorando a sua visão sobre um parto já simbolizado por sofrimento e dor física, levando ao temor sobre o atendimento na hora do parto. ${ }^{4}$

Na maioria das vezes, os profissionais que acompanham os partos não estão aptos para tratarem dessa dor de uma forma não invasiva, ou seja, com massagens, redução da luz, exercícios, música, dentre outros. Desse modo, a lher fica amedrontada, pois já está em um ambiente que não lhe é familiar, 
com profissionais que realizam uma série de intervenções comprovadamente desnecessárias e, tudo isso, faz com que o trabalho de parto seja mais demorado e sofrido. ${ }^{3}$

O alívio da dor deve ser uma prioridade para os profissionais de saúde, sendo feito através de métodos farmacológicos e não farmacológicos. A partir disso, torna-se indispensável que o profissional de saúde busque compreender a dor conforme o contexto sociocultural de cada mulher, tendo uma visão holística, favorecendo o cuidado obstétrico humanizado, oportunizando uma participação ativa da gestante e atendendo as suas necessidades, de acordo com suas expectativas em relação à dor e ao parto.

Desse modo, este estudo tem o objetivo de conhecer a percepção da mulher frente à dor do parto, a fim de auxiliar estudantes da área de saúde, profissionais e população em geral a conhecer o processo do parto, a dor do parto e possibilitar a construção de formas de cuidado baseadas em evidências científicas e humanísticas.

\section{Metodologia}

Trata-se de um estudo descritivo, exploratório, de abordagem qualitativa que refere-se a um conjunto de diferentes técnicas interpretativas que visam a descrever e a decodificar os componentes de um sistema complexo de significados, traduzindo e expressando o sentido dos fenômenos do mundo social, reduzindo a distância entre indicador e indicado, entre teoria e dados, entre contexto e ação. ${ }^{5}$

O estudo foi realizado entre os meses de julho a agosto de 2016, no Hospital esus Nazareno (HJN), em Caruaru-PE, o qual utilizou-se do critério intencional para a escolha do local da pesquisa, pelo fato de se tratar de uma instituição de úde referência para a assistência ao parto. 
A pesquisa contou com a participação de 13 mulheres, as quais foram abordadas após terem vivenciado o parto normal na instituição. Os pesquisadores se dirigiram até elas em alguns momentos, apresentaram a temática que estava sendo pesquisada, seus objetivos e finalidade. Em seguida, após a leitura e assinatura do Termo de Consentimento Livre e Esclarecido (TCLE), os pesquisadores se dirigiram para um local reservado para a entrevista, onde foi realizado individualmente, em sessão única.

Durante a pesquisa, obteve-se a perda de uma participante, pelo fato da mesma não querer dar continuidade a pesquisa. No mais, a amostragem total se deu pelo critério de saturação, onde os pesquisadores perceberam que os discursos das mulheres se assemelharam.

Foram incluídas no estudo as mulheres que se encontravam no pós-parto mediato e imediato e que passaram pela experiência do parto normal de baixo risco, sendo o recrutamento realizado a partir de visitas nos alojamentos conjuntos. Excluíram-se as mulheres que passaram pela cesariana.

Utilizou-se um roteiro como instrumento de coleta de dados, o qual foi elaborado pelos pesquisadores de acordo com os objetivos do estudo, composto pelas seguintes questões norteadoras: "Como foi a experiência no parto?", "O que você acha sobre a dor do parto?" e “Como você pensava que seria essa dor?". A entrevista foi realizada pelos pesquisadores que passaram por um treinamento de como conduzir a entrevista de modo a não induzir nas respostas. Ressalta-se que os discursos foram gravados de forma individualizada em dois gravadores diferentes, o qual durou em média 15 minutos cada entrevista. Seguindo-se da transcrição das entrevistas na grelha de análise de conteúdo em um arquivo do Microsoft Word.

A análise de dados aconteceu após a realização de toda a coleta, onde todos discursos foram verificados duas vezes, comparando a escrita com a gravação 1 das participantes. A interpretação das falas se deu a partir da técnica de 
análise de conteúdo na modalidade temática, considerando as seguintes etapas de análise ${ }^{6}$ :

Figura 1. Fases da Análise de Conteúdo Temática de Bardin.

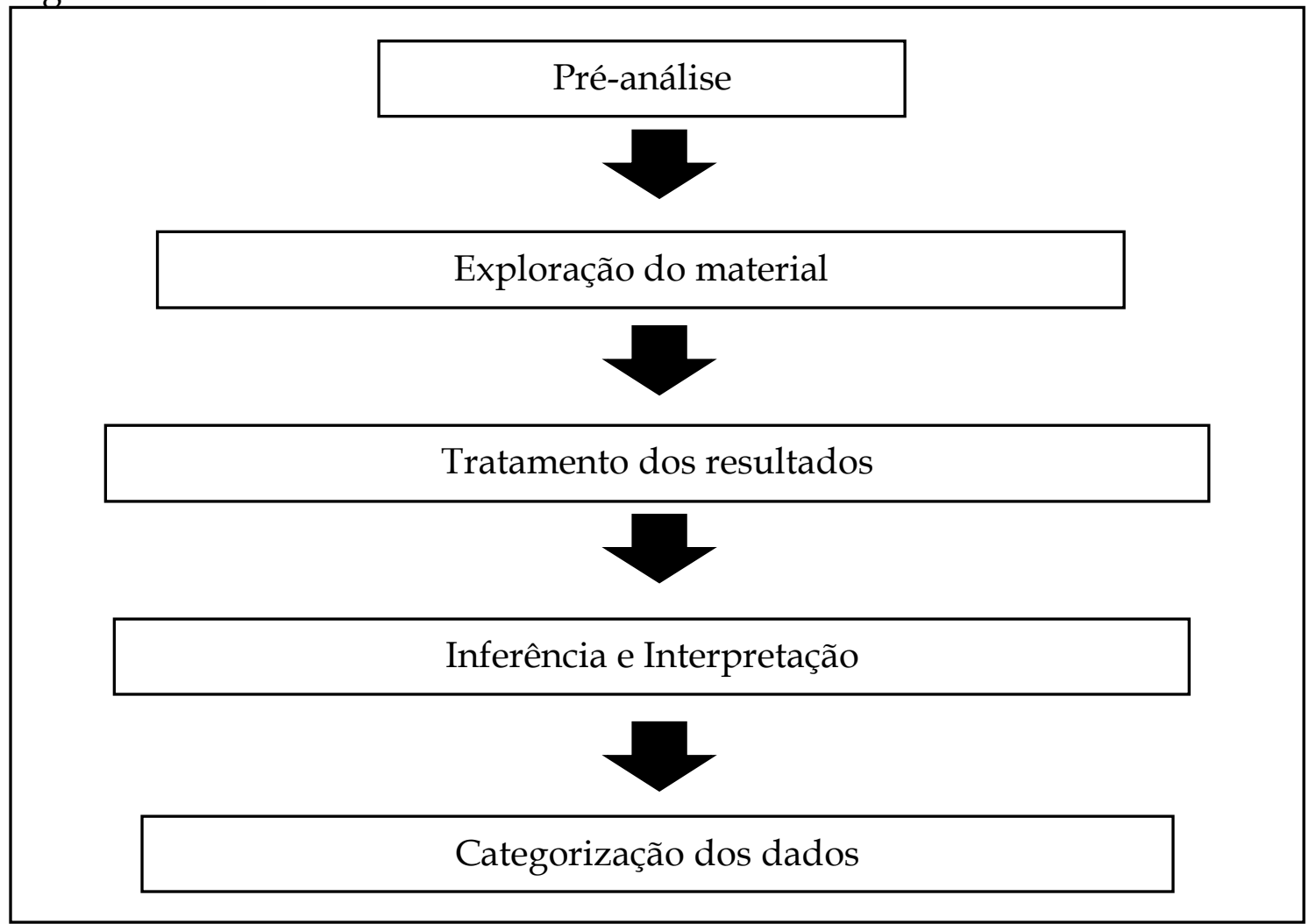

A partir disso, a análise das diferentes percepções resultou na identificação de duas unidades temáticas, estruturadas conforme a árvore de codificação (quadro 1).

Quadro 1. Descrição da árvore de codificação.

\begin{tabular}{|l|l|}
\hline Unidades Temáticas & Temas presentes \\
\hline $\begin{array}{l}\text { Unidade Temática I: O significado } \\
\text { negativo da dor durante o parto }\end{array}$ & $\begin{array}{l}\text { Dor insuportável e inexplicável, Dor } \\
\text { punitiva ao olhar divino. }\end{array}$ \\
\hline $\begin{array}{l}\text { Unidade Temática II: O significado } \\
\text { positivo da dor durante o parto }\end{array}$ & $\begin{array}{l}\text { Dor tolerável e passageira, } \\
\text { Recuperação rápida, Emoção, } \\
\end{array}$ \\
Experiência prazerosa. \\
\hline
\end{tabular}


A pesquisa foi avaliada pelo Comitê de Ética e Pesquisa do Centro Universitário Tabosa de Almeida ASCES-UNITA, obtendo aprovação segundo o parecer $\mathrm{n}^{\circ}$ 1.588.564/2016. Atendeu-se às exigências do Ministério da Saúde, na Resolução 510/2016 que considera o respeito pela dignidade humana e pela especial proteção devida aos participantes das pesquisas científicas envolvendo seres humanos. Informa-se que os participantes foram identificados pela letra $\mathrm{E}$ (entrevistado), seguida de uma sequência numérica referente à ordem da realização das entrevistas (E1, E2 ...), garantindo o anonimato das falas.

\section{Resultados}

Dentre as 13 mulheres que participaram do estudo, a faixa etária variou de 16 a 37 anos, 7 mulheres eram multíparas, 6 primigestas e a escolaridade variou entre fundamental incompleto e ensino médio incompleto. Após a análise de conteúdo das falas, emergiram duas categorias temáticas: "O significado negativo da dor durante o parto" e "O significado positivo da dor durante o parto".

\section{O significado negativo da dor durante o parto}

A dor sentida biologicamente esteve fortemente representada nas falas das entrevistadas, caracterizando-a como algo inexplicável, intolerável, superando até idealizações formadas antes do período expulsivo, conforme relatos abaixo:

"Sei lá uma dor insuportável (...)". (E2)

"É uma dor horrível, é demais (...)". (E3)

"Uma dor muito grande (...) sai queimando tudo quando a cabeça vai passar, o ombro também. Aí queima tudo, a pessoa sente rasgando também". (E9)

"Uma dor sem explicação né? A gente acha que é uma dor pequena, mas quando chega é outra dor, uma dor que a gente não consegue explicar, mas que dar pra aguentar". (E10) 
Outro fator identificado nas análises foi a designação divina de que a mulher tivesse a missão de ser mãe, ou seja, seu corpo foi preparado fisiologicamente para gerar um novo ser no seu ventre e trazê-lo ao mundo, porém, a partir da dor sentida no parto. Dor esta caracterizada como punitiva ao olhar divino. Este fato pode ser verificado em algumas falas a seguir:

"Sei lá uma dor insuportável que ... só coisa de Deus mesmo, né? Deus fez a gente assim, pra sofrer (...)". (E2)

"Porque foi Deus quem fez e se Ele fez, Ele sabe o que faz (...)". (E13)

Considera-se então, que as mulheres passam pelo ciclo gravídico e, em consequência disso, estão destinadas a sentir a temida dor do parto que, embora seja considerada intolerável, é um processo natural, pois Deus deu o dom à mulher de parir.

\section{O significado positivo da dor durante o parto}

A dor do parto está rodeada por diversos sentimentos que são reconhecidos a partir da experiência vivida. Estes sentimentos, ao contrário do que se pensa logo quando se aborda o tema, podem ser de ordem satisfatória, ligada ao prazer e sensação de superação de cada mulher.

"É pelo medo ou pela coragem de ter a criança. A vontade de ter ela não é tão dolorida assim, como as pessoas diz (...)". (E1)

"É bom porque a gente sabe que tudo passa (...) a gente vai realizar o sonho de ter um amor pra vida toda". (E7)

"É uma dor satisfatória, é uma dor prazerosa, porque é o momento que você sabe que você vai conhecer quem tanto você esperou, quem tanto você carregou durante aquele tempo todo com aquela expectativa de encontrar. Você sabe que vai ser seu eterno amor $e$ (...) é o momento mais bonito que eu acho que existe pra uma 
mulher, porque é uma dor que você sabe (...) Eu estou ali naquela luta, mas eu vou botar a vida mais importante do mundo, a vida que eu gerei (...)". (E14)

Algumas mulheres referiram que após o parto, existe uma grande recompensa que é ter seu filho nos braços. Para elas, o desejo de vivenciar a maternidade faz com que compreendam a dor como processo essencial para que haja o recebimento do filho tão esperado, conforme falas a seguir:

"A gente sente muita dor, mas depois que tem é muito emocionante, a gente esquece até da dor com a emoção, aí nem lembra mais da dor." (E11)

A dor também foi caracterizada como algo rápido, fácil de ser esquecida, sendo reduzida quando seu filho nasce.

"Mas é uma dor relevante que na hora que a criança nasce some tudo. Num tem mais dor nenhuma como se tivesse normal só fica incomodando a barriga, mas depois passa". (E3)

"Não é tão dolorido assim como as pessoas diz. É uma coisa rápida $(\ldots)^{\prime \prime} .(E 1)$

"Depois que a criança nasce ela passa né? Enquanto ela tá dentro, você tá sofrendo, mas depois que saiu, pronto, alívio totalmente." (E4)

Esta redução da dor também é apresentada como positiva, já que após o parto, a mulher não vai mais "sofrer com dor", como seria numa cesariana.

\footnotetext{
"Mas em compensação é bom. Você fica boa depois. Só a dor é naquele momento mesmo". (E2)

"É uma dor que vocể se recupera mais rápido que uma cesárea, eu prefiro entendesse, é normal". (E1)
} 
Nos relatos das mulheres fica claro que toda essa etapa dolorosa é algo passageiro e, mesmo que em meio à dor, de alguma forma conseguem se adaptar e quando tudo se finaliza percebem que aquela experiência é única. De acordo com os trechos das entrevistas:

"Só realmente mulher guerreira consegue ter um filho, porque né todo mundo que aguenta não (...)". (E2)

"Porque a gente sabe que tudo passa (...)". (E7)

"É boa porque valeu a pena todo sofrimento (...)". (E7)

"Na hora a gente pensa que não consegue, mas consegue (...)". (E7)

"Eu sei que senti dor né, mas depois saber a gente vai ter uma coisa pra vida toda, pra mim foi um prazer uma experiência muito grande (...)". (E10)

Durante a análise foi considerado que o parto não é só um processo fisiológico como também é psicológico e ambiental e que estes repercutem na progressão positiva ou negativa do parto, por isso deve-se atentar que os sentimentos e o meio interferem na forma como a parturiente irá se portar no parto.

\section{Discussão}

As percepções da dor do parto normal reproduzidas no contexto sociocultural e assistencial, são retratadas como fenômeno natural, inerente ao parto, caracterizada como progressiva, intensa, temporária, variável, desconfortável e tolerável. 7

No estudo presente, as mulheres atribuíram a dor do parto normal com o significado negativo no sentido de ser uma experiência inexplicável, horrível, uma dor insuportável. Em um outro estudo, ela foi caracterizada durante o rabalho de parto e o parto, como dor aguda especialmente no parto vaginal e, olorida e em cólica em ambos. Quanto à localização, a queixa mais comum foi 
dor no baixo ventre e lombossacra nas puérperas de parto vaginal, e nas cesarianas dor no baixo ventre, lombossacra e abdômen. ${ }^{8}$

Como também, em um estudo recente que entrevistou 31 puérperas que passaram pela parturição normal, na maternidade de um Hospital Público do município de Franca. Observou-se que a experiência da parturição foi percebida pela maioria das mulheres como extremamente dolorosa e sofrida, compensada, no entanto, pela atenção, apoio e carinho recebidos de alguns profissionais e acompanhantes, que contribuíram para uma visão satisfatória do parto normal. Entre os profissionais evidenciou-se dificuldade em conceituar sobre a temática da humanização do parto. ${ }^{9}$

Sob esse olhar positivo das mulheres que enfrentaram o parto normal nesse estudo, percebeu-se que as mesmas consideraram a experiência prazerosa diante de uma dor satisfatória e passageira, com uma recuperação rápida e regada de emoções. Dessa forma, a atenção dada pelos profissionais às parturientes é um aspecto fundamental do atendimento humanizado e se estabelece a nível técnico, humanizador, intuitivo e relacional. ${ }^{10}$

Considera-se então, que a intensidade da dor sentida pelas mulheres no trabalho de parto e parto é amplamente variável, e está sujeita a influências psíquicas, temperamentais, culturais, orgânicas e aos possíveis desvios da normalidade (estresse). A percepção da dor pode variar de acordo com as expectativas da gestante, podendo ser maior quando associada à decepção ou à sensação de fracasso da paciente que se preparou para um trabalho de parto sem dor. ${ }^{11,12}$

É também interpretada sob diferentes formas e influenciada por diversos fatores como cultura, história familiar, ansiedade, medo e experiência anterior, formações, entre outros o qual irá variar de mulher para mulher, com isso a arturiente não deve ser censurada pelo seu despreparo e sim ser respeitada e onselhada a condições para que possa suportar a dor. ${ }^{13}$ Considerando-se 
também em outro estudo que analisou a percepção de enfermeiras sobre o parto normal, a dimensão religiosa, considerando o parto normal como um momento divino que gera força e superação na mulher no período expulsivo. ${ }^{14}$

Com isso, o parto é um evento que marca profundamente a história das mulheres, gerando expectativas em relação ao momento do nascimento, criando intensas fantasias e ansiedades frente a um momento muito esperado, mas cercado pelo imprevisível, marcando profundamente a vida das mulheres, seja pelas emoções positivas ou negativas experimentadas. ${ }^{15}$

\section{Conclusões}

Ressalta-se a relevância do estudo para a assistência ao parto, por buscar compreender a percepção da mulher frente à dor do parto e todos os fatores que influenciam no trabalho de parto, sendo estes uma boa assistência e um ambiente favorável, especialmente para aquelas que vivenciaram o parto normal.

Em relação ao significado negativo da dor do parto segundo as mulheres, consideraram ser uma experiência inexplicável, horrível e uma dor insuportável. Entretanto, outras avaliaram positivamente a dor, como um momento prazeroso diante de uma dor tolerável e passageira, com uma recuperação rápida e regada de emoções. Dessa forma, no que se refere a significação da dor do parto segundo as mulheres, considera-se que esse processo é visto diante de várias representações e de forma individualizada, sendo uma experiência única na vida da mulher.

Contudo, considerou-se como limitações do estudo, o número reduzido de publicações que retratassem a percepção das mulheres quanto a dor exclusivamente no parto normal, sugerindo-se dessa forma, a realização de novos estudos nesse contexto. 


\section{Referências}

1. Bíblia. Português. Bíblia Sagrada. Gêneses. São Paulo (SP): Editora Ave-Maria Ltda; 2010.

2. Tornquist CS. Armadilhas da nova era: natureza e maternidade no ideário da humanização do parto. Rev Estud Fem. 2002 Jul-Dez;10(2):483-492.

3. Nascimento NM, Progianti JM, Novoa RL, Oliveira TR, Vargens OMC. Tecnologias não invasivas de cuidado no parto realizadas por enfermeiras: a percepção de mulheres. Esc Anna Nery. 2010 Jul-Set;14(3):456-461.

4. Progianti JM. Parteiras, médicos e enfermeiras: a disputada arte de partejar. [Dissertação]. Rio de Janeiro: Universidade Federal do Rio de Janeiro; 2001.

5. Neves JL. Pesquisa qualitativa: características, usos e possibilidades. Cad Pesqui em Adm São Paulo. 1996;1(3):1-5.

6. Bardin L. Análise de conteúdo. Lisboa: Edições 70, 2011.

7. Almeida NAM, Medeiros M, Souza MR. Sentidos da dor do parto normal na perspectiva e vivência de um grupo de mulheres usuárias do Sistema Único de Saúde. Rev Min Enferm. 2012;16(2):241-250.

8. Rett MT, Oliveira DM, Soares ECG, Santana JM, Araújo KCGM. Satisfação e percepção de dor em puérperas: um estudo comparativo após parto vaginal e cesariana em maternidades públicas de Aracaju. ABCS Health Sci. 2017; 42(2):6672 .

9. Pinheiro BC, Bittar CML. Percepções, expectativas e conhecimentos sobre o parto normal: relatos de experiência de parturientes e dos profissionais de saúde. Aletheia. 2012 Jan-Abr; 37:212-227.

10. Barros MLF. Percepção dos profissionais de saúde e das mulheres sobre o tipo de parto: revisão de literatura. Rev Enferm UFPE. 2011;5(2):496-504.

11. Nilsen E, Sabatino H, Lopes MHBM. Dor e comportamento de mulheres durante o trabalho de parto e parto. Rev Esc Enferm USP. 2015;45(3):557-565.

Santana LS, Gallo RBS, Marcolin AC, Quintana SM. Avaliação da intensidade dor na fase ativa do trabalho de parto em primigestas. Rev Dor. 2016;11(3):214217. 
13. Mafetoni RR, Shimo AKK. Métodos não farmacológicos para alívio da dor no trabalho de parto: revisão integrativa. REME. 2014;18(2):505-512.

14. Albuquerque NLA, Mendonça EF, Guerra MCGC, Silva JCB, Lins HN. Representações sociais de enfermeiras da atenção básica sobre o parto normal. Rev Ciênc Plu. 2019;5(1):34-51.

15. Tostes NA, Seidl EMF. Expectativas de gestantes sobre o parto e suas percepções acerca da preparação para o parto. Temas Psicol. 2016;24(2):681-693. 